\title{
National History Contributes to the Definition of National Identity*
}

\author{
Tibor Pólya \\ Hungarian Academy of Sciences, Budapest, Hungary
}

\begin{abstract}
The study empirically tests the claim that national history contributes to the definition of national identity. Definition of national identity was assessed by the analysis of narratives of historical events gained from 260 participants. The results show that national history plays a part in the definition of national identity.
\end{abstract}

Keywords: national identity, national history, self-categorization theory, narrative construction

Recently, increasing theoretical interest has been shown to how national history contributes to the definition of national identity (Finell \& Liebkind, 2010; László, 2013; Liu \& Hilton, 2005; Liu \& László, 2007; Smeekes, 2014). History provides resources to define national identity (Wertsch, 2002). History contains the ontogeny (Liu \& Hilton, 2005) and other defining moments of national history which shows up a critical moment "in which the nation was truly itself" (Reicher \& Hopkins, 2001, p. 139). History also encompasses the exemplary behaviours of key figures or heroes. Generalizations over history, such as charters (Liu, \& Hilton, 2005) and templates (Wertsch, 2002) also add to the definition of national identity.

However, empirical evidence is constrained regarding the defining role of history. There are studies showing that when persons are asked about the definition of national identity they most frequently refer to tradition and heritage (e.g., Cinnirella, 1997). Correspondingly, Smeekes (2014) found that persons' views on national history are associated with inter-group attitudes.

The aim of this study is to gather empirical evidence of the claim that history contributes to the definition of national identity. According to the Self-categorisation theory (Turner, Hogg, Oakes, Reicher, \& Wetherell, 1987), when a person identifies with a social identity category, that identity category becomes activated and defines the current self. If history contributes to the definition of national identity, we may expect that the level of identification with the national identity is related to a cognitive activity whose subject is representations of history such as constructing a historical narrative. More specifically, it could be expected that high identifiers construct a more complex historical narrative than low identifiers since representations of history are activated in their current self.

The expected relationship is likely to be affected by the valence of the narrated event. There is considerable research evidence (e.g., Semin, 2000) showing that the valence of the event is systematically

\footnotetext{
*Acknowledgements: The study was funded by National Research, Development and Innovation Office, grant No. 109009. The study was conducted within the framework of COST Action IS1205 "Social psychological dynamics of historical representations in the enlarged European Union".

Tibor Pólya, Institute of Cognitive Neuroscience and Psychology, Research Centre for Natural Sciences, Hungarian Academy of Sciences.
} 
related to the use of linguistic features. Since the social identification process is partly motivated by striving for positive self-esteem, it could be expected that when the historical event is positive, the narrator is more motivated to become active in the narrative construction, resulting in a narrative with a more complex structure. However, if the historical event is negative, a negative relationship is expected: the narrator is less motivated in narrative construction that results in a less complex structure.

Regarding the complexity of the historical narrative, the study focuses on the feature of perspective. Perspective includes the mental states of either the character or the narrator presented in the narrative. Accordingly, two types of perspectives (character and narrator perspective) will be analysed. Inclusion of either of them makes the narrative more complex (e.g., László et al., 2013).

Based on this, it is hypothesised that the level of identification and narrative complexity reflected by perspective are positively related when telling about a positive historical event, and they are negatively related when telling about a negative historical event.

\section{Study}

\section{Participants}

The study involved 260 Hungarian undergraduate students (64 men, 196 women). Their mean age was 22.07 years $(S D=3.74)$. Participants were recruited from psychology classes and their participation was voluntary.

\section{Instrument}

The level of identification with the Hungarian national identity category was measured by 7 Likert-type items regarding the subjective experiences related to national identity. Participants were asked to indicate the extent to which they agreed with each statement on a 7-point scale ranging from (1) "Completely disagree" to (7) "Strongly agree". Examples of items are "I feel strongly attached to Hungarians" and "Being Hungarian is not an important part of who I am" (reversed item). The internal consistency of the measurement was good $(\alpha=$ $0.75)$.

\section{Procedure}

The study was conducted in small groups. The participants' task was to recount the most important event from the history of Hungary in written form. They also rated the items measuring their identification with the national group. The order of presentation of the narrative writing task and identification measurement was counterbalanced. Completion of the tasks took about 20 minutes.

\section{Analysis of Narratives}

Short answers were omitted since they had no narrative structure. The cut point was at 18 words. For this reason, 26 cases were not included in the analysis. The valence of the events was coded as positive, negative or neutral by two independent coders. Many of the narratives contained both positive and negative information and the coders had to decide whether the historical event was dominantly positive or negative $(\kappa=0.63)$. Disagreements were resolved by the inclusion of a third coder. Neutral narratives were also omitted from the analysis $(N=14)$. The final sample included 220 narratives, 137 accounts of positive events and 83 accounts of negative events.

Perspective was analysed with an automated content analytical toolkit of Narrative Categorical Content Analysis (László et al., 2013). The character's perspective is revealed by words which describe characters' 
cognitions (e.g., think, make a decision), perceptions (e.g., see, hear) or emotions (e.g., sad, happy). The narrator's perspective was identified by the use of the first person singular pronoun. For statistical data analysis, relative measures were computed, that is, raw frequencies of the coded words were divided by the total word count of the narrative.

\section{Results}

In sum, 14 different historical events were mentioned. The three most frequently selected events covered almost two thirds of the narratives. These events were the Founding of the state (25.8\%), the Treaty of Trianon (24.6\%), and the Revolution of 1956 (13.1\%).

Mean identification was $4.17(S D=1.05)$. In order to test whether the presentation order of the tasks (narrative writing and identification measurement) had any effect on the level of identification, the two conditions were compared by independent-samples $t$-test. No difference in identification was found $(t<1)$. It was also assessed whether the level of identification was related to the choice of historical event and its valence. The sample was divided into two groups of high and low identifiers at the sample mean. Chi-square tests showed no difference between high and low identifiers in the choice of historical event $\chi^{2}(13)=14.57, p=$ $0.335)$. However, there was a marginal difference in the valence of the selected historical events $\left(\chi^{2}(1)=3.22, p\right.$ $=0.073)$. High identifiers chose more than twice as many positive historical events $(N=83)$ as negative ones $(N=40)$.

The average length of the narratives was 60.7 words $(S D=32.61)$. The relative frequency of character's and narrator's perspective was $1.26(S D=1.81)$ and 1.28 percent $(S D=1.59)$, respectively. Pearson correlation analysis was conducted including the level of identification and the relative frequencies of the two perspective measures. The results are reported in Table 1 where data are broken down according to the valence of the historical event.

Table 1

Correlation coefficients Among the Variables of Level of Identification and Perspective

\begin{tabular}{lll}
\hline & & Level of identification \\
\cline { 2 - 3 } Perspective & Negative event & Positive event \\
& $N=83$ & $N=137$ \\
\hline Character's perspective & $r$ & $r$ \\
Cognition & $-0.15^{+}$ & $0.15^{*}$ \\
Emotion & $-0.20^{*}$ & 0.08 \\
Narrator's perspective & -0.01 & $0.18^{*}$ \\
\hline
\end{tabular}

Notes. ${ }^{*} p<0.05,{ }^{+} p<0.10$.

Results on character's perspective are in line with the hypothesis. When narrating a positive historical event, identification correlates positively with the frequencies of character's perspective and reference to characters' emotions whereas in the case of negative events, there is a negative correlation between identification and references to characters' cognition in the narrative. Results on the narrator's perspective are also in line with the hypothesis: The correlation is positive in the case of positive historical events, and it is negative in the case of negative historical events.

\section{Discussion}


This study aimed to empirically test the idea whether national history contributes to the definition of national identity. More specifically, we attempted to reveal whether the level of identification with the national group is related to the construction of historical narratives. In consistence with our prediction, it was found that the level of identification is positively correlated with the complexity of the account of a positive historical event while the correlation between identification and complexity is negative in the case of negative historical events.

The results can be explained by suggesting that the activation of national identity involves the activation of its representational contents related to national history that results in the construction of a complex historical narrative. However, due to the correlational design of the study, we could not infer to the direction of a possible causal relationship between identification and construction of a historical narrative. There is empirical evidence showing that the presentation of pictures of national historical events can be used to make that identity category salient (Finell \& Liebkind, 2010). Alternatively, it is also plausible that narrative construction and identification interact. In line with this interpretation, the order of presentation of the narrative writing task and identification measurement had no effect either on narrative construction or on the level of identification.

Regardless of the direction of the relationship, the study provides empirical evidence of the conclusion that history is a part of the definition of national identity. This conclusion is in line with earlier approaches which stressed that history provides events and characters to exemplify important features of the national identity (Cinnirella, 1997; László, 2013; Liu \& Hilton, 2005; Reicher \& Hopkins, 2001; Smeekes, 2014; Wertsch, 2002). As an extension of previous studies which relied on verbal reports to uncover the contents of national identity, this study used verbal reports to assess the activity of representations of national identity in the current self. This extension corroborates the position that national history serves to define national identity.

This position is also confirmed by the results related to the motive for positive self-esteem (e.g., Turner et al., 1987). The finding that high identifiers prefer positive historical events to negative ones can be explained by the need for positive self-esteem. Furthermore, the study also found that the very construction of historical narratives is affected by this motive. These results reveal that national history contributes to the definition of national identity in such a way as to satisfy the positive self-esteem motive related to the activated national identity category.

The study highlights the importance of history education to define national identity, however, it has got several limitations. It was conducted with a homogeneous sample of university students. The study had a correlational design and it included only one national identity category, namely, the Hungarian national identity. These limitations make us cautious about generalizing the results without further empirical evidence.

\section{References}

Cinnirella, M. (1997). Towards a European identity: Interactions between the national and European identities. British Journal of Social Psychology, 36(1), 19-31.

Finell, E., \& Liebkind, K. (2010). National symbols and distinctiveness. British Journal of Social Psychology, 49, $321-341$. DOI: $10.1348 / 014466609 X 455190$

László, J. (2013). Historical tales and national identity: An introduction to narrative social psychology. London: Routledge.

László, J., Csertő, I., Fülöp, É., Ferenczhalmy, R., Hargitai, R., Lendvai, P., Péley, B., Pólya, T., Szalai, K., Vincze, O., \& Ehmann, B. (2013). Narrative language as an expression of individual and group identity: The narrative categorical content analysis. SAGE Open, April-June, 1-12. DOI:10.1177/2158244013492084

Liu, J. H., \& Hilton, D. J. (2005). How the past weighs on the present: Social representations of history and their role in identity politics. British Journal of Social Psychology, 44, 1-21. 
Liu, J. H., \& László, J. (2007). A narrative theory of history and identity: Social identity, social representations, society and the individual. In G. Moloney, \& I. Walker (Eds.), Social representations and history (pp. 85-107). New York: Palgrave-Macmillan.

Reicher, S., \& Hopkins, N. (2001). Self and nation: Categorization, contestation and mobilization. London: Sage.

Semin, G. R. (2000). Agenda 2000-Communication: Language as an implementational device for cognition. European Journal of Social Psychology, 30(5), 595-612.

Smeekes, A.N. (2014). The presence of the past. Historical rooting of national identity and current group dynamics. Doctoral dissertation, Utrecht University.

Turner, J. C., Hogg, M. A., Oakes, P. J., Reicher, S. D., \& Wetherell, M. S. (1987). (Eds.). Rediscovering the social group: A self-categorization theory. Oxford: Blackwell.

Wertsch, J.V. (2002). Voices of collective remembering. Cambridge: Cambridge University Press. 